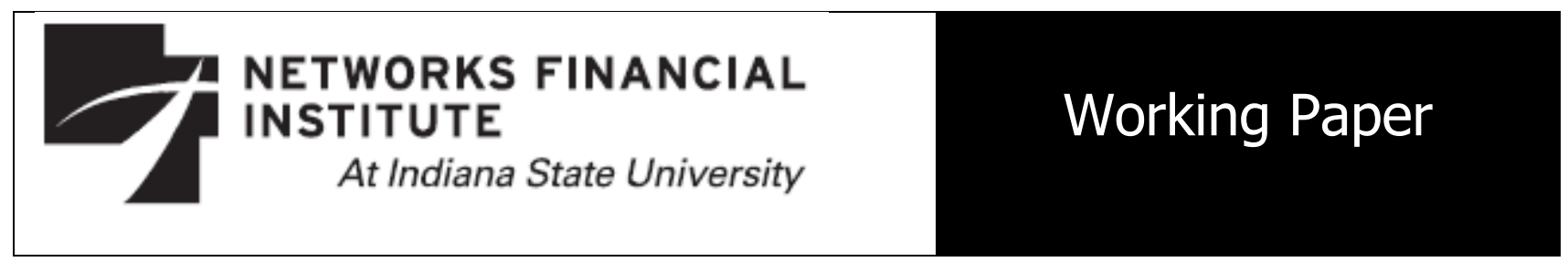

2010-WP-06

November 2010

\title{
Starting a New Chapter: The Role of Credit Counseling in Helping Debtors Recover from Bankruptcy
}

Angela C. Lyons, Shawn Howard and Eric Scherpf

Abstract: The 2005 Bankruptcy Abuse Prevention and Consumer Protection Act (BAPCPA) includes two educational provisions which require debtors to complete an approved credit counseling course prior to filing for bankruptcy and a financial education course prior to the discharge. Recent debates have raised concerns about the counseling mandate and whether debtors are benefiting from the requirement. A multi-phase research study was launched in 2009 to investigate the impact of BAPCPA's educational mandates. The goal was to track debtors through the entire bankruptcy process and assess the long-term impacts of the requirements on debtors' financial well-being. This study reports the findings from the first phase of the analysis where data were collected from a national sample of debtors who participated in a bankruptcy counseling course offered by one of the largest full-service nonprofit consumer credit counseling agency in the U.S. The purpose of the study was to measure the "educational value" of the counseling and to identify specific groups of debtors who were more likely than others to benefit from the experience. The results show that overall debtors were very satisfied with their counseling experience. Moreover, their financial knowledge, attitudes, and behavioral intentions significantly improved as a result of the counseling. The effects of the counseling were primarily dependent on debtors' prior knowledge, behavior, and socioeconomic status, as well as the circumstances that resulted in their current financial problems. There was little, if any, evidence to suggest that the counseling requirement had been a burden or an administrative obstacle.

About the Authors: Angela C. Lyons is an Associate Professor in the Department of Agricultural and Consumer Economics at the University of Illinois at Urbana-Champaign. She received her Ph.D. in economics from the University of Texas at Austin. Her research focuses on issues related to household economics and finance, with particular emphasis on financial education and program evaluation. She is widely published in leading research journals and has been interviewed by numerous media sources including The Wall Street Journal, U.S. News \& World Reports, CBS Market Watch, CNN, and Money Magazine. She serves on editorial boards for the Journal of Consumer Affairs, the Journal of Financial Counseling and Planning, and the Journal of Personal Finance. She also has served on numerous advisory boards for organizations such as the American Council on Consumer Interests, Money Management International, and MasterCard International. She is currently the Director for the University of Illinois Center for Economic and Financial Education and the editor for The Journal of Consumer Education. Shawn M. Howard is a Statistician for Money Management International, the nation's largest non-profit credit counseling agency. He received his M.S. in statistics from the University of Houston - Clear Lake. His current research focuses on financial education and has had past work published in the Journal of Occupational and Environmental Medicine. Erik M. Scherpf is an Economist with the USDA Economic Research Service. He received his Ph.D. in economics from the University of Illinois at Urbana-Champaign. His research interests include household financial behavior, income volatility and food assistance programs.

Keywords: Bankruptcy, financial education, credit counseling.

JEL Classifications: D10, D14, D18.

This paper is based on an unpublished report released in May 2010 by Money Management International, Inc. (MMI) titled "In Search of a Fresh Start: Can Credit Counseling Help Debtors Recover From Bankruptcy?" The views expressed are those of the individual author(s) and do not necessarily reflect official positions of Networks Financial Institute or MMI or any of their members or staff. Data collection of this study is funded by National Endowment for Financial Education. The authors thank Chuanyi Tang for his excellent research assistance. Please address questions regarding content to Angela Lyons at anglyons@illinois.edu. Any errors or omissions are the responsibility of the authors. NFI working papers and other publications are available on NFI's website (www.networksfinancialinstitute.org). Click "Thought Leadership" and then "Publications/Papers." 


\section{Starting a New Chapter: The Role of Credit Counseling in Helping Debtors Recover from Bankruptcy}

In 2005, Congress passed the Bankruptcy Abuse Prevention and Consumer Protection Act (BAPCPA). The Act includes two educational provisions. ${ }^{1}$ First, debtors are required to complete a credit counseling session prior to filing for bankruptcy. After filing, they are then required to complete a financial education course before they are permitted to discharge their debts. According to the legislative history of the Act, these requirements were included to ensure that consumers were able to make an informed choice about bankruptcy, its alternatives, and consequences (U.S. Government Accountability Office, 2007). They were also included to provide debtors with the financial skills necessary to better manage their money and avoid future financial problems.

Since BAPCPA went into effect, there has been considerable discussion surrounding the educational requirements. Debates have emerged among policymakers, legal professionals, and consumer advocacy groups as to whether the requirements are in fact helping debtors to improve their financial well-being. The counseling requirement in particular has come under scrutiny. Some have raised concerns that the counseling mandate places undue administrative and financial hardship on debtors who are already overwhelmed financially (e.g., Loonin, Rao, and SoRelle 2007). They argue that the requirement is serving more as an administrative obstacle, especially for those who are on the verge of losing their homes and have no other option but to file for bankruptcy. Concerns have also been raised that the counseling requirement has the potential to expose consumers to abusive practices by credit counseling agencies (Loonin, Rao, and SoRelle 2007; U.S. Government Accountability Office 2007).

Proponents of the requirement assert that the counseling has educational value (for a general discussion, see Lyons, White, and Howard (2008) and U.S. Government Accountability Office

\footnotetext{
${ }^{1}$ For more details on BAPCPA and the education requirements, see the Administrative Office of the United States Courts (2006) and the United States Trustee Program (2010a).
} 
(2007)). They argue that repealing the counseling requirement would prevent debtors from getting the assistance they need to develop the knowledge and skills to better manage their finances and build future financial security. They point out that this is the only mechanism currently available at the national level to ensure that financially overwhelmed debtors receive some type of educational assistance. Furthermore, proponents assert that the counseling can provide the financial guidance and support that debtors need to deal with their financial problems and obtain a fresh start. The end result is likely to be a reduction in debtors' overall stress and an improvement in their long-term financial security.

To date, though, much of this debate has been speculative. Very little research has been conducted to empirically test the actual effectiveness of the counseling requirement, and in particular, its educational impact. Research is needed to learn more about the effectiveness of the counseling requirement. Do debtors in fact benefit from the counseling experience? Can the counseling play a role in helping debtors recover financially from bankruptcy? Also, are there specific groups of debtors who are benefiting more than others from the counseling experience?

In 2009, a multi-phase research study was launched to investigate the impact of BAPCPA's educational requirements. The overall goal of the study was to track debtors through the entire bankruptcy process and then follow up with them to assess the long-run impact of the counseling and education requirements on debtors' overall financial well-being. This study focuses on presenting the findings from the first phase of the analysis. In the first phase, data were collected from a national sample of debtors who participated in a bankruptcy counseling course offered by one of the largest providers of bankruptcy counseling and education in the U.S. The purpose of this first phase was to measure the educational impact of the counseling experience and to estimate a series of regressions to identify specific groups of debtors who may be benefiting more than others from the counseling requirement. 
The findings from this study have important implications for researchers, policymakers, legal professionals, financial educators, and consumers. From a policy perspective, the results provide insight into whether the counseling requirement is serving its intended purpose. From an educational perspective, the findings provide valuable insight into how the requirement is helping to improve debtors' personal financial situations.

\section{LITERATURE REVIEW}

Consumer credit counseling has long been considered the best alternative to filing for bankruptcy (Lown 2005). For over 50 years, credit counseling organizations have been assisting consumers in dealing with their financial problems. ${ }^{2}$ When the industry first began in the 1960s, it focused on offering two core services: (1) one-on-one budget/financial counseling with a recommended plan of action and (2) debt management plans (DMPs), where a credit counseling agency negotiates a repayment plan with creditors on behalf of the consumer. ${ }^{3}$

Today, agencies within the industry offer a much wider range of credit counseling and general financial education services at no, or very little, cost to debtors. These services have expanded beyond traditional budget analysis and DMPs to include community-based group education, homeownership counseling and education, as well as bankruptcy counseling and education. Consumers who seek out credit counseling services generally fall into one of three categories: (1) those who are able to help themselves out of financial trouble but are looking for solutions to handle the debt on their own; (2) those who need a debt management plan (DMP) to help them consolidate and repay their debts; and (3) those whose financial situation is so severe that

\footnotetext{
${ }^{2}$ See Hunt (2005) and Wang (2010) for a general overview of the history of the consumer credit counseling industry. ${ }^{3}$ Under a DMP, the consumer pays off their unsecured debts by making a single, consolidated payment each month to the credit counseling agency. The agency, in turn, distributes the payment to the consumer's creditors. The benefit of being on a DMP is that creditors often agree to lower a consumer's interest rates or waive certain fees as long as the consumer remains on the DMP. There is typically a cost of being on a DMP that goes toward helping the agency cover its expenses.
} 
bankruptcy may be their best, and perhaps only, option (Xiao and Wu 2006b). The question is does credit counseling really help to improve the financial outcomes of consumers?

There is a small but growing body of research that looks at the impact of traditional credit counseling on debtors' financial well-being. Most of this research was conducted prior to the implementation of the bankruptcy counseling requirement and so focuses on the first two groups of consumers - those looking to handle their financial problems on their own or those needing the assistance of a DMP. While these studies are not directly linked to the bankruptcy process per se, they provide insight into the potential impacts that the bankruptcy counseling requirement may have on debtors' financial outcomes.

One line of research uses data collected from individual credit counseling agencies to assess whether credit counseling can improve clients' overall well-being. These studies use more subjective socioeconomic measures to determine whether counseling helps to reduce financial stress, increase satisfaction levels, and improve credit management practices and other financial behaviors (e.g., Kim, Garman, and Sorhaindo 2003; Wang 2010; Xiao, Sorhaindo, and Garman 2006; Xiao and $\mathrm{Wu} 2006 \mathrm{a}$ ). The results of these studies tend to show a positive relationship between the credit counseling experience and clients' overall financial well-being.

Another line of research focuses on the impact that counseling has on more economic-based measures (e.g., Elliehausen, Lundquist, and Staten 2007; Staten and Barron 2009). These studies often track clients over time and use control groups to see if, and how, credit counseling affects clients' credit usage and repayment behaviors. The results generally show that participating in credit counseling can lead to positive financial outcomes such as debt reduction, lower incidences of delinquency and bankruptcy, and higher credit scores. These findings tend to be consistent across delivery methods (i.e., in-person, telephone, or Internet counseling). 
While the preceding studies provide evidence that the counseling experience may have a positive impact on debtors' financial circumstances, the results are based on samples of clients who voluntarily sought out credit counseling. Therefore, the results may be biased in favor of a positive counseling effect if those who actively choose to participate in the counseling are more motivated to improve their financial situation. Under BAPCPA, debtors who want to file bankruptcy are required to complete credit counseling and do not have a choice about whether they want to participate. For this reason, one might expect the effects of the bankruptcy counseling to be understated.

To date though, very few studies have conducted empirical research to investigate the impacts of the bankruptcy counseling requirement. ${ }^{4}$ Existing research has primarily focused on evaluating the operational and legal aspects of the counseling such as defining goals, setting appropriate standards and acceptable metrics for evaluation, and implementing effective delivery strategies (e.g., Clancy and Carroll 2007; Loonin, Rao, and SoRelle 2007; U.S. Government Accountability Office 2007). These studies, however, provide little insight into the actual educational value of the counseling and its impact on debtors' financial outcomes.

Thorne and Porter (2007) asked families that filed bankruptcy prior to 2005 whether taking a money or debt management course would have helped them to avoid bankruptcy. Over half of the respondents reported that a financial management course would have helped them to avoid bankruptcy. This finding suggests that debtors seem to perceive value in completing an educational course such as a credit counseling session. However, this is speculative since it is based on debtors' perceptions rather than actual measurable outcomes.

\footnotetext{
${ }^{4}$ Note that the U.S. bankruptcy counseling and education requirements are similar to those implemented by Canada in 1992. Under the Canadian requirements, debtors must complete two mandatory financial counseling sessions (Ramsay 2002; Schwartz 2003). Reviews of the Canadian model though have been mixed. Some studies have reported thay the counseling sessions are useful and may positively impact debtors' future financial stability (e.g., Ramsay 2002). Other studies such as Schwartz (2003) conclude that the counseling requirements are not likely to lead to appreciable improvements in debtors' credit profiles and future creditworthiness.
} 
In 2006, the National Foundation for Credit Counseling (NFCC) surveyed its member agencies that had been approved to provide bankruptcy counseling and found that some of its members had administered pre- and post-tests to their bankruptcy counseling clients. These agencies reported that their clients had experienced positive gains in knowledge and improvements in satisfaction levels, attitudes, and behavioral intentions as a result of the counseling. Unfortunately, it is unclear how many agencies administered the surveys, what evaluation methods and survey content they used, and whether they used similar outcome measures to capture gains in knowledge, attitudes, and behaviors. Given this, it is not possible to assess the overall quality of the NFCC's reported findings. In its report, the NFCC acknowledged the limitations of these findings and called for more evaluative research.

Lyons, White, and Howard (2008) have been among the first to attempt to measure the educational value of the counseling experience by using more formalized evaluation methods (i.e., pre- and post-tests) and outcome-based measures (i.e., changes in knowledge, attitudes, and behaviors). They showed that on average debtors who participated in the bankruptcy counseling experienced significant gains in financial knowledge. Moreover, they found significant and positive changes in debtors' planned (or intended) financial behaviors, such that debtors were ready and willing to take steps to improve their financial situation following the counseling. They also found that nearly all of the debtors were satisfied with their overall counseling experience (over 94.0 percent felt that their ability to manage their finances had improved and 99.0 percent would seek counseling again). Qualitative responses further revealed that debtors seemed to appreciate the educational value of the counseling and did not feel that the requirement had been a burden or an administrative obstacle.

Because the existing research on bankruptcy counseling is still in its infancy, and much of it is descriptive in nature, researchers need to be somewhat cautious in interpreting the findings of this 
work. Nevertheless, previous research provides a useful framework for conducting further investigation. This paper builds upon the existing literature and takes a more rigorous approach to quantifying the educational impact of the counseling. In particular, it identifies specific groups of debtors who may be more likely than others to benefit from the counseling experience.

\section{DATA COLLECTION}

\section{The Credit Counseling Course}

In October 2005, a nationally-recognized credit counseling agency was approved by the Executive Office for U.S. Trustees (EOUST) to provide bankruptcy counseling. ${ }^{5}$ The agency was widely recognized as having the largest share of the bankruptcy counseling market in 2009 (approximately 13.0 percent of the overall market). ${ }^{6}$ Originally, the agency offered bankruptcy counseling using two different delivery methods - in-person and telephone. In July 2006, it began offering bankruptcy counseling via an online course. To date, the agency continues to offer bankruptcy counseling via all three delivery methods. However, online counseling now represents the primary delivery method for bankruptcy counseling in the U.S. and currently represents over 50.0 percent of the agency's bankruptcy counseling sessions. It is estimated that in 2009 alone the agency provided bankruptcy counseling to 170,921 debtors, of which 87,269 debtors completed the counseling online.

To participate in the online course, bankruptcy attorneys either pre-registered their clients or the clients went directly to a centralized Web site and created an account. ${ }^{7}$ From here, the clients

\footnotetext{
${ }^{5}$ The mandatory bankruptcy counseling course must be obtained from an approved provider by the U.S. Department of Justice's U.S. Trustee program (United States Trustee Program 2010b). A list of approved providers can be accessed online at http://www.usdoj.gov/ust/eo/bapcpa/ccde/index.htm.

${ }^{6}$ The agency is also considered to be the largest nonprofit, full-service credit counseling agency in the U.S. Since 1958, it has provided a wide range of services to consumers to assist them in finding the tools and solutions they need to better manage their finances and achieve long-term financial security. In addition to bankruptcy counseling and education, its services include credit counseling, community-wide educational programs, debt management assistance, and housing counseling and education.

${ }^{7}$ The agency's fee for its online bankruptcy counseling session was $\$ 50.00$ in 2009 . The $\$ 50.00$ fee was for either a single filer or joint filers if both participated in the course at the same time. The agency waived the fee for debtors
} 
logged in and began the course. The course consisted of ten modules covering a wide range of basic personal finance concepts including: (1) income and expenses, (2) assets, liabilities, and net worth, (3) budgeting and tracking income and expenses, (4) keeping adequate financial records, (5) financial goal setting, (6) savings and emergency funds, (7) debt management options and strategies, (8) the bankruptcy process, (9) laws that protect debtors, (10) types of credit and the cost of credit, (11) credit reports and credit scores, and (12) establishing or re-establishing credit. The course also had a number of interactive components such as budgeting activities, financial calculators, check lists, and assessment tools.

The Web site for the course was available 24/7, and clients could log in and complete the course in one session or several sessions if that was more convenient. The course took about 60 to 90 minutes on average to complete. At the end of the course, clients were required to speak via phone with a certified counselor. The call generally lasted an average of 15 to 20 minutes. However, it could last up to 45 minutes depending on the clients' needs. During the call, the counselor reviewed key points covered in the course, gathered any additional information that was needed, and responded to clients' questions or concerns. At the end of the call, clients were issued a certificate of course completion. This certificate allowed them to proceed with the bankruptcy process, if they elected to do so.

To measure the educational impact of the online bankrutpcy counseling course, quantitative and qualitiatve data were collected using pre-and post-tests that were built into the online course. Responses to the pre- and post-tests were entered by the client and downloaded into a central database for future analysis.

\section{Financial Knowledge and Behavior Measures}

whose household income was equal to or less than 150 percent of the estimated poverty threshold for their applicable family size as published in the current Federal Poverty Levels Guidelines. 
The pre- and post-tests collected information on clients' level of financial knowledge, current financial practices, and future intended practices. To measure financial knowledge, clients were asked ten knowledge-based questions. ${ }^{8}$ The questions focused on testing key personal finance concepts covered during the counseling course (see Table 3 for the specific questions). All of the items were formatted as true/false questions. ${ }^{9}$ The same set of knowledge questions was included on both the pre- and post-tests. The questions were randomly re-ordered on the post-test to minimize the potential of learning bias. A knowledge score was calculated for each client pre- and postcounseling based on the percentage of questions they answered correctly. ${ }^{10}$ Scores ranged from 0 to 100 percent.

Financial behavior was measured by asking clients about their current and future intentions to engage in 12 financial practices (Table 4 presents the specific practices). These 12 practices were key behaviors emphasized during the online course. At the beginning of the course, clients were asked to report how often they were currently doing each financial practice. At the end of the course, they were then asked to report how often they planned to do each financial practice. Responses were based on a 5-point Likert scale, ranging from 1=Never to 5=Always. A total behavior score was calculated for each client by summing their responses to the 12 financial practices using the

\footnotetext{
${ }^{8}$ Evaluation experts typically recommend using 10 to 25 knowledge questions to establish a reliable baseline level of knowledge for an individual (Jayaratne, Lyons, and Palmer 2007). However, for short educational programs lasting two hours or less it is sufficient to use five to ten knowledge questions. Following these guidelines, the counseling course included 10 knowledge-based questions since the course lasted approximately 60 to 90 minutes.

${ }^{9}$ To capture changes in knowledge, researchers often use multiple choice or true/false questions. Both provide reliable measures of knowledge acquisition. The true/false format, however, can help to keep the evaluation tool brief and save on time needed to administer the survey since participants can respond to true/false questions faster than multiple choice (Jayaratne, Lyons, and Palmer 2007).

${ }^{10}$ Cronbach's Alpha was used to test the internal consistency and reliability of the questions used to construct the financial knowledge score. The test showed that the 10 knowledge questions were correlated (alpha was 0.69 for the post-test) and that the knowledge score was a reliable measure of overall financial knowledge based on the content of the credit counseling course. The 10 questions were also found to have conceptual validity in that they were consistent with those used and tested by previous researchers (e.g., Hilgert, Hogarth, and Beverly 2003; Jayaratne, Lyons, and Palmer 2007; Lyons, White, and Howard 2008).
} 
reported values from the 5-point Likert scale. ${ }^{11}$ A client's total behavior score could range anywhere from 12 to 60, with higher scores reflecting more positive financial behaviors or more positive behavioral intentions.

\section{Financial Events and Experiences}

Information was also collected on clients' past financial events and experiences, including the reasons for their current financial situation and actions already taken to deal with their financial problems. In addition, clients were asked about their willingness to take certain actions to improve their financial situation, such as whether they were willing to reduce expenses (e.g., stop eating out, eliminate vacations), increase income (e.g., get a second job, work more hours), or make other lifestyle adjustments (e.g., downsize to smaller home, move in with family/friends). At the end of the course, they were asked about specific steps they were planning to take to deal with their financial situation, including filing for bankruptcy. In addition, they were asked to report their overall satisfaction with the counseling and how likely they were to seek credit counseling again if they had financial problems in the future.

\section{Demographics}

Demographic information was collected on clients' age, gender, education, marital status, race/ethnicity, employment status, homeownership, and financial position (including household income, expenses, assets, and liabilities). ${ }^{12}$ Geographical information, including state, county, and zip code, was also gathered for each client based on the location of their residence in 2009. In addition, data from the 2000 Census were merged with the counseling data using clients' geographical information. Specifically, the following four Census measures were constructed to

\footnotetext{
${ }^{11}$ The reliability of the behavior items was also tested. Cronbach's Alpha showed that the 12 financial practices were strongly correlated (alpha was 0.83 for the pre-test and 0.93 for the post-test) and that the behavior score was a reliable measure of clients' overall financial behavior. The behavior items were conceptually valid as well (e.g., Hilgert, Hogarth, and Beverly 2003; Jayaratne, Lyons, and Palmer 2007; Lyons, White, and Howard 2008; O’Neill and Xiao 2003).

12 The information collected from clients on their asset and liability holdings was self-reported and subject to considerable biases related to non-response and reporting errors. Therefore, it was not included in the analysis.
} 
capture socioeconomic factors related to local neighborhood and community characteristics: (1) the percentage of the total population residing in an urban area within the client's county; (2) the percentage of the total population in the client's county that was unemployed; (3) the percentage with less than a high school education; and (4) the median house value for the client's county of residence. Note that the Census variables were constructed at the county level and are reported for the year 2000. ${ }^{13}$ Median house values for each county were converted to 2009 dollars using the Consumer Price Index.

\section{DESCRIPTIVE STATISTICS}

Between February and August 2009, data were collected from approximately 42,181 debtors who completed the agency's online bankruptcy counseling course. Of these, 9,627 observations were dropped due to missing or incomplete information. ${ }^{14}$ The final sample consisted of 32,554 debtors (77.2 percent of the original sample).

Table 1 presents the descriptive statistics for the sample. The majority of clients were between the ages of 36 and 55 (56.2 percent). A slightly larger percentage was male than female (53.4 percent compared to 46.6 percent). Over half of the sample reported that they were married (56.0 percent), while 21.4 percent were divorced or separated, 20.4 percent were single or never married, and 2.3 percent were widowed. In addition, the majority of clients reported that they were white (70.1 percent), 11.9 percent were Hispanic/Latino, 10.2 percent were African-American, 4.6 percent were Asian or Pacific Islander, and 3.2 percent were another race/ethnicity. With regard to education and income, most clients had at least a high school education (95.6 percent), with 67.8 percent reporting that they had some type of college education. Half of the sample (50.0 percent)

\footnotetext{
13 The socioeconomic variables were also constructed at the zip code level, but could only be constructed for clients in 2009 who resided in areas that had a 2000 zip code $(n=31,216)$. The results using the county-level data were similar to those found using the zip code level data and so the sample was not restricted. The results for the zip code level data are available upon request.

${ }^{14}$ The majority of observations were removed because clients chose not to respond to one or more of the knowledge or behavior questions on the pre- or post-test.
} 
reported annual household incomes of $\$ 40,000$ or less, with 30.9 percent reporting incomes between $\$ 20,001$ and $\$ 40,000$ and 19.1 percent reporting incomes that were $\$ 20,000$ or less. About 60.0 percent indicated that they were homeowners (57.7 percent). In addition, 65.4 percent reported that they were working full-time, 10.7 percent were working part-time, and 23.9 percent were not currently employed.

Table 1 also provides some general information on the geographical distribution of the sample based on clients' state of residence in 2009. About 17.0 percent reported that they lived in the Northeast, 22.6 percent in the South, 25.0 percent in the Midwest, and 35.0 percent in the West. It should not be surprising that the sample was weighted towards the West since it included states like Arizona, California, Nevada, and Utah, where bankruptcy filing rates in 2009 were particularly high.

These sample statistics are largely representative of the agency's overall population of counseling clients. However, the data were taken from a single credit counseling agency, so it may be difficult to generalize the findings to the larger population of approved providers of bankruptcy counseling, as well as to the larger population of U.S. debtors and bankruptcy filers. With this said, the agency is the largest nonprofit credit counseling agency in the country and offers bankruptcy counseling and education in all 50 states. Thus, the sample is likely to be fairly representative of the population of U.S. bankruptcy counseling clients as a whole.

\section{Financial Profile}

Table 2 provides a financial profile of the clients, including the reasons for their financial problems, past actions taken to deal with these problems, and willingness to take future actions to improve their situation. Clients most frequently attributed their financial problems to the following factors: unexpected expenses (74.1 percent), loss of employment (52.1 percent), unnecessary spending (49.8 percent), and health-related problems such as illness or injury (36.4 percent). Other 
factors included business loss or excessive business expenses (25.9 percent), divorce or separation (21.8 percent), and death of a spouse or other loved one (6.7 percent). These findings are consistent with other research (e.g., Lyons, White, and Howard 2008) which has found that debtors' financial problems were a combination of factors related to unexpected life events and poor financial management practices.

In the last 12 months, clients also reported the following events. Almost half (47.8 percent) reported that they had used one credit card to pay off another and 36.8 percent had delayed house or auto payment to make credit card payments. In addition, 29.7 percent had used a high interest rate loan (e.g., payday loan, rent-to-own, or title loan) while 24.9 percent had property repossessed or their home foreclosed on.

To deal with their financial problems, clients reported taking a number of actions. A large percentage of clients responded that they had reduced expenses ( 82.6 percent), borrowed money from family or friends (63.4 percent), and renegotiated terms and conditions of existing loans (47.1 percent). In addition, several clients had increased their income by working more hours or taking a second job (38.7 percent). Some also had consolidated debts (37.4 percent), cashed out or borrowed against their retirement funds (37.3 percent), and refinanced their home or applied for another loan (31.1 percent). Over one-quarter of the clients (28.2 percent) had sold their home, car, or other possessions. Several clients also reported that they had previously filed for bankruptcy (27.1 percent), contacted a credit counseling service (25.0 percent) or participated in a debt management plan (9.7 percent). Interestingly, a fairly large percentage (16.8 percent) indicated that they had not taken any action, or felt they had no options, to help them deal with their financial problems.

With regard to future actions, almost all of the clients (98.3 percent) indicated that they would be willing to reduce expenses (e.g., stop eating out, eliminate vacations). In addition, 78.5 percent would be willing to increase income (e.g., get a second job, work more hours) and 60.4 
percent would be willing to make lifestyle adjustments (e.g., downsize to a smaller home, move in with family/friends). These findings suggest that most debtors were aware of their behaviors at the counseling stage and open to taking action to fix their financial problems.

\section{Financial Knowledge and Behavior}

Table 3 presents clients' responses to the ten knowledge questions. The first column presents the percentage of debtors who answered each question correctly on the pre-test. The second column presents the percentage of debtors who answered the same set of questions correctly on the post-test. The final column reports the difference between the pre- and post-test scores (i.e., net change in knowledge) and whether these differences were statistically significant. In general, the findings show that clients' financial knowledge improved as a result of the bankruptcy counseling. For all ten questions, clients' financial knowledge significantly increased. On average, debtors' scored 77.1 percent on the pre-test and 85.9 percent on the post-test, for a net gain in knowledge of +8.8 percent. The overall percentage increase in knowledge was 11.4 percent. The greatest gains in knowledge occurred for questions related to debt-to-income ratios $(+19.7$ percent $)$, credit reports and the bankruptcy process $(+16.6$ percent), net worth and solvency $(+11.1$ percent $)$, and fixed and variable expenses $(+10.5$ percent). The smallest gains were found for questions related to secured versus unsecured loans $(+2.4$ percent $)$, laws that protect debtors $(+2.7$ percent $)$, and the cost of credit (+3.9 percent).

Table 4 presents the mean behavior scores for how often clients were engaging in 12 financial practices pre-counseling and how often they planned to engage in those same practices post-counseling (recall that scores ranged from 1=Never to 5=Always). Several findings are worth noting. Pre-counseling, clients were more likely to engage in financial practices that could be implemented irrespective of their financial situation. For example, mean behavior scores precounseling were 4.10 for "reviewing income and expenses before making large purchases," 4.08 for 
“comparing prices before making purchases," 3.79 for "reducing impulse spending and cutting unnecessary expenses," and 3.72 for "reviewing bills each month for accuracy." Clients were less likely to engage in behaviors that were more closely linked to their financial position and thus more difficult to implement. Mean behavior scores pre-counseling were 2.16 for "keeping your debt-toincome ratio below 20 percent," 2.18 for "saving money each month," and 2.56 for "using less than 50 percent of your available credit." It is likely that, at this point, clients' actions were still constrained by their financial situation and by the courts that were supervising them.

Following the counseling, clients overwhelmingly reported that they planned to engage in all 12 financial practices. Mean behavior scores were still lower for those practices that were more closely linked to the client's financial position. However, all of the scores were over 4.0, ranging from 4.44 for "saving money each month" to 4.84 for "reviewing income and expenses before making large purchases." These findings suggest that the counseling experience likely raised clients' awareness about their current financial practices and motivated them to want to change their future practices so as to improve their overall financial situation.

Table 4 also presents an average total behavior score, which was calculated by summing clients' responses to the 12 financial practices using the values from the 5-point Likert scale and then averaging the scores over the entire sample. Out of a total possible score of 60 , the average total behavior score for the sample was 39.2 pre-counseling and 56.4 post-counseling. These findings again confirm that the counseling experience likely had a positive impact on clients' attitudes and confidence levels, especially with regard to their willingness to apply what they had learned during the counseling to improve future behavior.

\section{Perceived Educational Impacts}

Clients were also asked about their overall counseling experience and whether they thought they had received educational benefit from the course. Table 5 summarizes clients' responses. As a 
result of the counseling, 98.0 percent of clients reported that they felt more knowledgeable about the bankruptcy process, and 97.4 percent felt more knowledgeable about the options available to deal with their current financial problems. In addition, 91.4 percent indicated that their overall ability to improve their financial behaviors had increased. With regard to general satisfaction, 99.4 percent of clients found the counseling course to be at least "somewhat helpful," with 44.3 percent reporting that the course was "very helpful." Similarly, 96.9 percent reported that they would be at least "somewhat likely" to recommend the course to others, with 40.2 percent being "very likely." In addition, over 97.0 percent would be at least "somewhat likely" to seek credit counseling again if they had financial problems in the future. Almost half (43.7 percent) would be "very likely" to seek credit counseling again.

\section{EMPIRICAL MODELS}

Based on the descriptive data, it appears that clients are likely benefiting educationally from the counseling. However, these descriptive findings only provide insight into the impact for the "average" client. Certain client characteristics may be driving these outcomes and a closer look at the data could reveal that some clients are benefiting more than others from the counseling. These factors could be related to debtors' prior knowledge, attitudes, behaviors and socioeconomic status. They could also be related to unexpected shocks and environmental factors outside of their control.

The specific relationship between the counseling effect and these various factors is a bit ambiguous. Chang and Lyons (2008) point out that clients' prior knowledge, behaviors, and unique experiences may facilitate learning due to a learning curve effect. In other words, those who start out with a more solid foundation in personal financial management may be able to gain more from the program because their prior knowledge allows them to more easily assimilate the program's content. At the same time, those who start out with a better foundation may also gain less from the counseling because by default they do not have as much room to improve. In this case, if the clients 
are already knowlegeable about the subject matter and they are already engaging (or intending to engage) in the behaviors, the counseling may be serving more as a reinforcement, or a reminder, of what they already know and what they need to be doing.

For this reason, it is important to assess how various client characteristics affect the counseling outcomes, especially for those who start out with a more solid financial management foundation. It is also important to consider the impact for those with higher socioeconomic status (i.e., higher income and education levels) since they are in a better position to recover postcounseling. Regressions were estimated using the pre- and post-test knowledge and behavior data to determine which clients were more likely to score higher on the financial knowledge test and to engage in more positive financial practices post-counseling.

With regard to knowledge, the following Ordinary Least Squares (OLS) model was estimated:

$$
\text { FKPost }_{i}=\alpha_{0}+\alpha_{1} \text { FKPre }_{i}+X_{i}^{\prime} \alpha_{2}+\varepsilon_{i}
$$

In this model, FKPost $t_{i}$ is the dependent continuous variable that represents the $i^{\text {th }}$ client's knowledge score on the post-test. The client's post-test score $\left(F K P\right.$ Post $\left.t_{i}\right)$ is expressed as a linear function of the client's pre-test score $\left(\right.$ FKPre $\left._{i}\right)$ and a vector of the client's personal characteristics $\left(X_{i}\right)$. The error terms, $\varepsilon_{i}$, are assumed to be random and normally distributed with mean zero. ${ }^{15}$

There are many factors that could potentially affect a clients' level of financial knowledge. The client's pre-test score $\left(\right.$ FKPre $\left._{i}\right)$ is included to account for the client's baseline level of financial knowledge prior to the course. ${ }^{16}$ Other independent variables $\left(X_{i}\right)$ are also controlled for in the

\footnotetext{
${ }^{15}$ Some researchers may be concerned about the potential for the error terms to be heteroskedastic. This model controls for the client's pre-test score and other personal characteristics, but the distribution of unexplained variation in the client's post-test score may still be dependent on the explanatory variables. Standard errors were adjusted so that they were robust to unknown forms of heteroskedasticity. The results from the unadjusted model were not significantly different from those of the adjusted model so concerns about heteroskedasticity are likely to be unwarranted.

${ }^{16}$ A client's baseline level of financial knowledge prior to counseling $\left(F K P r e_{i}\right)$ was assumed to be exogenous, because all individuals start out a priori with a certain level of financial knowledge. Theoretically, it is possible to test the assumption that $\mathrm{FKPre}_{i}$ is exogenous. However, to run this endogeneity test, we would need to estimate an equation for
} 
model, including a standard set of general demographics (age, gender, marital status, race/ethnicity, education, household income, homeownership, and employment status) and a dummy variable for whether clients are willing to make lifestyle adjustments to improve their financial situation. ${ }^{17}$ This variable is used to account for clients' aptitudes and preferences for learning and making change. It is hypothesized that those who are more willing to change at the outset will also be more likely to learn more from the course.

Also included in $X_{i}$ is a set of variables to account for previous financial events and experiences that could directly or indirectly affect clients' financial knowledge. These variables control for the reasons behind clients' current financial problems such as a negative health shock, loss of employment, or unnecessary spending. The model also controls for whether clients in the last 12 months used a payday loan or other high interest rate loan, delayed house or auto payments to pay credit card bills, and had property repossessed or home foreclosed. A final control is included to account for whether clients previously filed for bankruptcy. As previously mentioned, the relationship between these factors and the dependent variable is not exactly clear. On the one hand, some of these adverse events and experiences might reflect the greater propensity of clients with limited financial knowledge to commit errors, or otherwise make poor decisions, in their personal finances. On the other hand, they might lead to knowledge gains if clients were able to learn the appropriate lessons from them.

To account for community and neighborhood effects, the model also includes the four Census measures: (1) the percentage of the total population residing in an urban area within the client's county; (2) the percentage of the total population in the client's county that was unemployed;

FKPre $_{i}$ that includes a variable that does not affect FKPost ${ }_{i}$. Unfortunately given the limitations of our data, we were unable to conduct this type of test.

${ }^{17}$ Recall from Table 2 that the vast majority of clients were willing to reduce expenses and increase income (98.3 percent and 78.5 percent, respectively). Only 60.4 percent reported that they were willing to make lifestyle adjustments so this measure was included in the model since it allowed for greater variability in the estimates. 
(3) the percentage with less than a high school education; and (4) the median house value for the client's county of residence. Controlling for these factors helps to better isolate the "true" effects of the demographics, especially socioeconomic factors such as education, race/ethnicity, and employment. These controls also help to mitigate the possibility that the race/ethnicity variables may be picking up environmental, or neighborhood, effects associated with poor financial outcomes, such as living in urban "financial deserts," where access to financial services and products is limited.

To identify which clients were more likely to engage in positive financial practices, another OLS model was estimated for financial behavior:

$$
\text { FBPost }_{i}=\gamma \beta_{0}+\beta_{1} \text { FBPre }_{i}+X_{i}^{\prime} \beta_{2}+u_{i}
$$

In this model, FBPost $t_{i}$ is the dependent continuous variable that represents the $i^{\text {th }}$ client's total behavior score post-counseling. It is expressed as a linear function of the client's behavior score pre-counseling $\left(\mathrm{FBPr}_{i}\right)$ and the same vector of personal characteristics $\left(X_{i}\right)$ that were controlled for in the knowledge model. ${ }^{18} X_{i}$ is included because the same factors that are likely to affect financial knowledge are also likely to affect behavior. The error terms, $u_{i}$, are assumed to be random and normally distributed with mean zero.

\section{REGRESSION RESULTS}

Table 6 presents the OLS regression results for clients' financial knowledge and behavior. The first two columns present the results for clients' post-counseling knowledge. Recall that the knowledge score is based on the percentage of questions clients answered correctly. The next two columns present the results for planned (or intended) behavior post-counseling. Higher scores reflect more positive financial behavior. The coefficients and robust standards errors are presented for each model.

\footnotetext{
${ }^{18}$ As with knowledge, we assume that all individuals start out with a baseline level of financial behavior. For this reason, prior financial behavior $\left(F B P r e_{i}\right)$ was assumed to be exogenous in the behavior model. Standard errors were also adjusted so that they were robust to unknown forms of heteroskedasticity.
} 


\section{Financial Knowledge}

With regard to the first model, clients' prior financial knowledge, measured by their pre-test score, was positively related to their post-test score. Thus, those who started off with more knowledge scored higher on the post-test than those who started with less knowledge, holding all other factors constant. ${ }^{19}$ The demographic characteristics revealed that younger clients scored significantly higher than older clients, with those less than 36 years of age scoring highest. Females though were significantly less likely than males to score higher. With respect to marital status, those who were divorced/separated or widowed scored significantly higher than those who were single. A somewhat troubling finding was the large negative effects found for minorities. Relative to whites, each racial/ethnic group scored significantly lower on the post-test. The largest negative effect was found for Hispanics.

The findings also showed that socioeconomic status was a key determinant of knowledge. Specifically, clients with higher levels of education attained significantly higher post-test scores; those with less than a high school education scored the lowest. Post-test scores also increased with income. Those with incomes over $\$ 80,000$ experienced the largest gains when compared to those with incomes below $\$ 20,000$. Homeowners were more likely to score higher as well. Employment status though did not significantly affect clients' knowledge levels.

The effects of clients' attitudes and past financial experiences were mixed. Clients' willingness to make lifestyle adjustments did not significantly affect their post-test score. However, the reasons for clients' current financial problems were found to significantly and positively affect

\footnotetext{
${ }^{19}$ A probit model also was estimated to determine which characteristics were more likely to affect the probability that clients had at least a "basic" or "satisfactory" level of financial competency by the end of the counseling course. The basic level of competency was defined according to whether clients scored 70.0 percent or better on the post-test. The results were similar to those found for the OLS model. An interesting difference, though, was that the magnitude of the effect for prior knowledge was larger in the probit model than in the OLS model. This result suggests that for a given level of pre-counseling knowledge it may be easier to achieve incremental gains in financial knowledge than it is to achieve a more substantial improvement from unsatisfactory to satisfactory. The probit results are available from the authors upon request (see also Lyons, Howard, and Scherpf (2010)).
} 
their scores. Those whose financial problems were due to health problems or loss of employment were significantly more likely to score higher. Similarly, those whose financial problems were due to unnecessary spending were also more likely to score higher. Thus, clients' financial knowledge seems to have increased regardless of whether their indebtedness resulted from unfortunate circumstances beyond their control or from poor financial management practices.

There is also evidence to suggest that other financial events may have affected knowledge levels. Clients who used a payday or other high-interest rate loan scored significantly lower, as did those who delayed house or auto payments to pay off credit card balances. Having property repossessed or home foreclosed or having previously filed for bankruptcy were factors that were also associated with lower scores, but these effects were statistically insignificant. Thus, some of these "negative" events and experiences may be signaling that some clients were in particularly dire financial straits. They may also have had extremely low levels of financial competency. In any case, these events may have put them in a position financially where they were unable to gain as much, or believe that they gained as much, from the counseling experience as others.

The controls for county-level socioeconomic factors also yielded some interesting results. Clients living in counties with a larger urban population scored lower, as did those living in counties with a higher percentage of residents who had less than a high school education. Those living in counties with higher median housing values also scored lower, which is somewhat counterintuitive. However, median housing values may be controlling for financial conditions in the marketplace rather than socioeconomic effects. In particular, these values may be capturing the effect of the housing bubble. Areas with higher housing values in 2000 were likely to have been hit harder by the collapse of the housing market and the subsequent financial crisis in 2008. Debtors living in these areas may have been living in a more economically-challenged community in 2009 when the data were collected. 


\section{Financial Behavior}

The results of the second model show that clients' pre-counseling behavior scores had a significant and positive effect on clients' post-counseling behavior scores, where the post scores reflected degree of behavioral intention. In looking at the demographics, the coefficients for each age category were positive but statistically insignificant. Nevertheless, the magnitudes suggest that younger clients were more willing to change their behaviors following the counseling. Female and married clients were also more willing to positively change their behaviors. However, compared to whites, each racial/ethnic group reported significantly lower behavior scores. Asians had the lowest scores. The findings for the socioeconomic factors were as expected. Clients with higher levels of education had significantly higher behavior scores, as did homeowners. Post-behavior scores also increased with income.

The results related to attitudes and financial experiences showed that clients who were more willing to make lifestyle adjustments were also significantly more likley to report their intention to engage in more positive financial behaviors post-counseling. The reasons for clients' current financial problems were also found to significantly and positively affect their post-behavior scores. Those whose financial problems were due to health problems or loss of employment were significantly more likely to report better behavioral intentions. Similarly, those whose financial problems were due to unnecessary spending were also more likely to have better behavioral intentions. This finding is similar to that found for financial knowledge.

Other financial events affected behavioral intentions as well. Clients who used a payday, or other high-interest rate, loan had significantly higher post-scores. These findings suggest that some "negative" experiences may help clients become more aware of their financial behaviors and learn from these negative experiences. On the other hand, some experiences may negatively affect behavioral intentions. For example, those who previously filed for bankruptcy reported significantly 
lower behavior scores post-counseling. It may be that clients who previously went through the bankruptcy process, and who once again found themselves on the brink of bankruptcy, were more pessimistic about their ability to successfully implement positive behavior change after the counseling.

The controls for county-level socioeconomic factors revealed that clients living in counties with higher median house values were significantly more likely to report lower behavior scores post-counseling. Those living in counties with larger urban populations and with higher percentages of residents with less than a high school education also reported lower behavior scores. However, these effects were statistically insignificant. In any case, these findings could be an indication that those living in economically-challenged communities may have greater obstacles they need to overcome before they can successfully implement change.

Overall, the findings from the behavior model suggest that while several factors affected clients' behavioral intentions, the magnitudes of these effects were fairly small. Similar to the model for financial knowledge, the largest effects were those found for socioeconomic factors such as education, income and race/ethnicity. The fact that the effects were small in magnitude is perhaps not surprising for a couple of reasons. First, the models focus on intended (or planned) behavior rather than actual behavior change. Most clients were not yet in a position to implement actual behavior change because they had not yet filed for bankruptcy and discharged their debts. Second, given the magnitude of some clients' financial problems, a 60-to-90 minute counseling session may not have been sufficient to make a significant difference. In other words, those with more severe financial problems may require more intensive intervention and treatment.

\section{DISCUSSION}

\section{What Have We Learned?}


This study used data collected from a national sample of bankruptcy counseling clients to measure the educational value of the counseling and to identify specific groups of debtors who were more likely than others to benefit from the experience. The initial descriptive analysis revealed that debtors' financial knowledge, attitudes, and behavioral intentions improved as a result of the counseling. Pre- and post-tests showed that most debtors were fairly knowledgeable prior to the counseling. Yet, they still showed significant improvement in overall financial literacy after the counseling. On average, debtors scored 77.1 percent correct on the pre-test and 85.9 percent correct on the post-test for an increase in knowledge of 11.4 percent. In addition, over 97.0 percent reported after the counseling that they felt more knowledgeable about the bankruptcy process and the options available to deal with their current financial problems. Over 91.0 percent felt that their overall ability to manage their finances had improved.

The results also showed that post-counseling debtors appeared to be at a "teachable moment" where they were more aware of their current financial practices and were motivated to want to take action to improve their financial situation. In addition, prior to counseling, debtors were more likely to engage in behaviors that were independent of their financial position and thus more easily implemented. By the end of the counseling, debtors overwhelmingly reported that they planned to engage in all of the financial behaviors, regardless of the degree to which these behaviors were tied to their financial means.

In general, debtors were also very satisfied with their counseling experience. Over 99.0 percent found the counseling course helpful and about 97.0 percent indicated they would be likely to seek counseling again if they had financial problems in the future. Additional qualitative data (not presented in this paper) revealed that almost all debtors seemed to appreciate the educational value of the counseling and did not feel that the requirement had been a burden or an administrative 
obstacle (Lyons, Howard, and Scherpf 2010). It is particularly noteworthy that the clients responded in such a positive way to a mandatory counseling session.

Regression analysis further showed that specific groups of clients were more likely than others to benefit from the counseling experience. The first key finding was that knowledge and behaviors prior to counseling resulted in significant improvement in clients' knowledge and behaviors following counseling. This result suggests that clients' prior foundation in personal financial management is likely to affect the degree to which the counseling is able to help them recover financially following bankruptcy.

Second, debtors' socioeconomic status also seemed to play a key role. Those with higher incomes and education were significantly more likely to experience improvements in knowledge and behavioral intentions. Thus, having more education and income (human capital and resources) may put individuals in a better position to recover financially post-counseling.

The reasons for debtors' financial problems were also key determinants of knowledge and behavior. Half of all debtors reported that their financial situation was due to unnecessary spending. Compared to those whose financial situation was not due to financial mismanagement, these debtors were more likely to become financially knowledgeable and to indicate that they would be more likely to engage in positive financial behaviors post-counseling. Those whose financial problems were due to unfortunate circumstances such as illness and unemployment were also more likely to experience improvements in financial knowledge and behavioral intentions. These findings suggest that, on average, debtors benefited from the counseling regardless of whether their indebtedness resulted from unfortunate circumstances beyond their control or from poor financial management practices.

Finally, the regression results found negative effects associated with race/ethnicity. Compared to whites, minorities tended to fare worse in terms of financial knowledge and behavior. 
These negative effects persisted even after controlling for individual and community-based socioeconomic factors. One plausible explanation for the adverse results for Hispanic clients is that there may have been a language barrier. The online bankruptcy counseling course was offered in both English and Spanish. However, clients had to select which version of the course they preferred when they registered. If they did not select Spanish, they were automatically registered for the English version of the course.

It seems unlikely, though, that a language barrier can entirely explain differences in race/ethnicity, especially for African Americans. Another explanation might be that the Census measures used to control for neighborhood and community effects were unable to adequately control for some socioeconomic factors such as differences in access to financial services and products. The effects for race/ethnicity could also be picking up attitudinal and cultural differences. For example, some groups of debtors may have been so discouraged by their current financial situation that they felt their situation was hopeless and out of control. These debtors may have been less confident and more pessimistic going into the counseling, which could have affected their performance and responses during the counseling course. Thus, some of the effects associated with race and ethnicity may not have anything to do with the counseling itself.

\section{Implications for Policy and Education}

The findings from this study have important implications for public policy and education. From a policy perspective, the results provide valuable insight into whether the counseling requirement is serving its intended purpose. The educational requirements were included in the 2005 bankruptcy reform legislation to assist debtors in making an informed choice about bankruptcy and to provide them with the financial skills necessary to better manage their money and avoid future financial problems. Opponents of the counseling requirement have argued that it is serving as an administrative obstacle to those who are already overwhelmed financially and who 
have no other option but to file for bankruptcy. They further argue that debtors' financial problems are primarily the result of unexpected life events that may have little to do with their financial management skills (e.g., Block-Lieb, Gross, and Wiener 2002).

The empirical evidence presented in this study paints a different picture. The results show that over 97.0 percent of debtors felt more knowledgeable about the bankruptcy process and the options available to deal with their financial problems as a result of the counseling. In addition, the evidence suggests that debtors seemed to benefit from, and find value in, the counseling regardless of whether their financial problems were due to unanticipated circumstances outside of their control or poor financial management practices. Thus, the counseling experience likely provides some sort of "teachable moment" to assist debtors in acquiring the financial knowledge and skills needed to obtain a fresh start and establish long-run financial security. Furthermore, this study has shown that specific groups of debtors (based on their demographics, individual circumstances, and reasons for filing) may be more likely than others to benefit from the experience. Thus, a "one-size-fits-all" approach to bankruptcy counseling may not be ideal for all debtors (Lyons, White, and Howard 2008, Wang 2010).

But how specifically might the counseling experience be improved to better assist debtors? Recall that a large proportion of debtors already knew many of the key concepts covered in the counseling course. This is perhaps not surprising since the course covered very basic financial management concepts. While many debtors already knew these basic concepts, their knowledge was still found to improve as a result of the counseling. Thus, counseling may have the potential to generate larger educational gains if it were better tailored to debtors' specific financial needs. For example, clients who are already knowledgeable about the subject matter, and in a better financial position to improve their behaviors post-bankruptcy, may benefit more from a "fresh start" counseling session. This session might place more emphasis on topics such as using credit wisely, 
rebuilding credit, checking and monitoring credit reports and credit scores, avoiding predatory lending practices, and being financially prepared for the unexpected.

Moreover, clients with more severe knowledge and behavioral deficiencies may require more intensive educational support and training to help them get back on track financially. Depending on the reasons for, and severity of, their current financial problems, a 60-to-90 minute counseling session may not be enough to have a lasting impact on debtors' long-term financial security. Realistically, some debtors may require a series of financial counseling or "financial coaching" sessions that help them lay out a financial action plan where they set personalized financial goals and are provided regular motivation and support for achieving those goals.

Finally, when BAPCPA went into effect in 2005, the primary forms of delivery for the counseling session were in-person and telephone. However, consumer demand, and issues related to delivery costs and efficiency, quickly resulted in the development of Internet-based courses. Some have questioned whether online counseling is as effective as in-person and telephone counseling. This study provides evidence that online counseling has likely had a positive impact on the financial knowledge, attitudes and behavioral intentions of debtors. Moreover, the impacts appear comparable to those found for phone and in-person counseling (e.g., Lyons, White, and Howard 2008). From an educational perspective, online counseling appears to be an effective means of delivery.

\section{Summary}

This study is among the first to formally measure the educational value of bankruptcy counseling and to identify specific groups of debtors who may be more likely than others to benefit from the experience. What happens to these debtors after they file for bankruptcy remains to be seen. Are they able to actually put into practice what they learned from the counseling? Addressing this question is beyond the scope of this initial phase of analysis. Yet, the results have shown that 
debtors appear to be deriving educational benefit from the counseling experience and seem to be satisfied with the services they are receiving. Also, they appear to have good behavioral intentions following the counseling, even though external constraints may still prevent them from being able to implement certain behaviors - no matter how much education they receive. As this study has shown, those constraints may be related to such factors as prior knowledge, experiences, and socioeconomic status. Thus, our research lays an important foundation that other researchers can build upon to determine whether bankruptcy counseling is, in fact, a viable mechanism to help debtors deal with their financial situation and obtain the fresh start that they need. 


\section{REFERENCES}

Administrative Office of the United States Courts. 2006. Bankruptcy Basics. Washington, DC: Author. http://www.uscourts.gov/bankruptcycourts/bankruptcybasics.html.

Barron, J. M. and M. E. Staten. 2009. Is Technology-Enhanced Credit Counseling as Effective as In-Person Delivery? (Working paper). Tucson, AZ: Take Charge America Institute for Consumer Financial Education and Research, University of Arizona.

Block-Lieb, S., K. Gross, and R. L. Wiener. 2002. Lessons from the Trenches: Debtor Education in Theory and Practice. Fordham Journal of Corporate \& Financial Law, 7 (2): 503-523.

Chang, Y. and A. C. Lyons. 2008. Are Financial Education Programs Meeting the Needs of Financially Disadvantaged Consumers? Journal of Personal Finance, 7 (2): 84-109.

Clancy, N. and S. J. Carroll. 2007. Prebankruptcy Credit Counseling. Santa Monica, CA: RAND Corporation. http://www.rand.org/pubs/technical_reports/2007/RAND_TR509.pdf.

Elliehausen, G., E. C. Lundquist, and M. E. Staten. 2007. The Impact of Credit Counseling on Subsequent Borrower Behavior. The Journal of Consumer Affairs, 41 (1): 1-28.

Hilgert, M. A., J. M. Hogarth, and S. G. Beverly. 2003. Household Financial Management: The Connection Between Knowledge and Behavior. Federal Reserve Bulletin, July, 309-322.

Hunt, R. M. 2005. Whither Consumer Credit Counseling? Business Review, Q4, 9-20. Philadelphia, PA: Federal Reserve Bank of Philadelphia.

Kim, J., E. T. Garman, and B. Sorhaindo. 2003. Relationships Among Credit Counseling Clients' Financial Well-Being, Financial Behaviors, Financial Stressor Events, and Health. Financial Counseling and Planning, 14 (2): 75-87.

Jayaratne, K. S. U., A. C. Lyons, and L. Palmer. 2007. Financial Education Evaluation Manual. Greenwood Village, CO: National Endowment for Financial Education. http://www2.nefe.org/eval/intro.html.

Loonin, D., J. Rao, and M. SoRelle. 2007. New Burdens but Few Benefits: An Examination of the Bankruptcy Counseling and Education Requirements in Massachusetts. Boston, MA: National Consumer Law Center. http://www.consumerlaw.org/reports/content/Bankruptcy_Burdens.pdf.

Lown, J. M. 2005. Educating and Empowering Consumers to Avoid Bankruptcy. International Journal of Consumer Studies, 29 (5): 401-408.

Lyons, A. C., S. Howard, and E. Scherpf. 2010. In Search of a Fresh Start: Can Credit Counseling Help Debtors Recover from Bankruptcy? Houston, TX: Money Management International. 
Lyons, A. C., T. White, and S. Howard. 2008. The Effect of Bankruptcy Counseling and Education on Debtors' Financial Well-Being: Evidence from the Front Lines. Houston, TX: Money Management International.

National Foundation for Credit Counseling. 2006. Consumer Counseling and Education Under BAPCPA: The Bankruptcy Abuse Prevention and Consumer Protection Act of 2005, Year One Report. Silver Spring, MD: Author.

O’Neil, B. and J. J. Xiao. 2003. Financial Fitness Quiz: A Tool for Analyzing Financial Behavior. Consumer Interests Annual, 49.

Ramsay, I. 2002. Mandatory Bankruptcy Counseling: The Canadian Experience. Fordham Journal of Corporate and Financial Law, 7 (2): 525-541.

Schwartz, S. 2003. The Effect of Bankruptcy Counseling on Future Creditworthiness: Evidence from a Natural Experiment. The American Bankruptcy Law Journal, 77 (3): 257-283.

Thorne, D., and K. Porter. 2007. Financial Education for Bankrupt Families: Attitudes and Needs. The Journal of Consumer Education, 24: 15-27.

United States Government Accountability Office. 2007. Bankruptcy Reform: Value of Credit Counseling Requirement is Not Clear (GAO-07-203). Washington, DC: Author. http://www.gao.gov/new.items/d07203.pdf.

United States Trustee Program. 2010a. Bankruptcy Abuse Prevention and Consumer Protection Act of 2005 (BAPCPA). http://www.usdoj.gov/ust/eo/bapcpa/index.htm.

United States Trustee Program. 2010b. Credit Counseling \& Debtor Education Information. http://www.usdoj.gov/ust/eo/bapcpa/ccde/index.htm.

Wang, J. J. 2010. Credit Counseling to Help Debtors Regain Footing. The Journal of Consumer Affairs, 44 (1): 44-69.

Xiao, J. J., B. Sorhaindo, and E. T. Garman. 2006. Financial Behaviors of Consumers in Credit Counseling. International Journal of Consumer Studies, 30 (2): 108-121.

Xiao, J. J. and J. Wu. 2006a. Applying the Theory of Planned Behavior to Retain Credit Counseling Clients. In Proceedings of the Association for Financial Counseling and Planning Education, edited by D. C. Bagwell, (91-101). Columbus, OH: Association for Financial Counseling and Planning Education.

Xiao, J. J. and J. Wu. 2006b. Encouraging Behavior Change in Credit Counseling: An Application of the Transtheoretical Model of Change (TTM) (Working paper). Tucson, AZ: Take Charge America Institute for Consumer Financial Education and Research, University of Arizona. 
TABLE 1

Demographic Profile of Online Bankruptcy Counseling Clients $(N=32,554)$

Mean Percentages

Age

Under 26

26-35 $23.9 \%$

$36-45 \quad 31.8 \%$

46-55 24.4\%

Over $55 \quad 16.1 \%$

Gender

Female $\quad 46.6 \%$

Male $\quad 53.4 \%$

Marital Status

Married $\quad 56.0 \%$

Divorced/Separated $\quad 21.4 \%$

Single/Never married $\quad 20.4 \%$

Widowed

$2.3 \%$

Race/Ethnicity

Caucasian/White

African-American/Black

Hispanic/Latino

$10.2 \%$

$11.9 \%$

Asian/Pacific Islander $\quad 4.6 \%$

Other

$3.2 \%$

Education Level

Less than high school

High school (or GED)

Some college

College or graduate degree
Household Income (before taxes)

Less than $\$ 20,000 \quad 19.1 \%$

$\$ 20,001-\$ 40,000 \quad 30.9 \%$

$\$ 40,001-\$ 60,000 \quad 25.3 \%$

$\$ 60,001-\$ 80,000 \quad 14.2 \%$

Over $\$ 80,000 \quad 10.5 \%$

Homeownership (\%)

Homeowner $\quad 57.7 \%$

Non-homeowner $\quad 42.3 \%$

Employment Status

Working full-time $\quad 65.4 \%$

Working part-time $\quad 10.7 \%$

Not currently working $\quad 23.9 \%$

Region of the country where debtors reside ${ }^{a}$

Northeast: New England Division $\quad 6.3 \%$

Northeast: Middle Atlantic Division $\quad 11.0 \%$

South: South Atlantic Division $\quad 12.5 \%$

South: East South Central Division $\quad 2.9 \%$

South: West South Central Division $\quad 7.2 \%$

Midwest: East North Central Division $\quad 20.7 \%$

Midwest: West North Central Division $\quad 4.3 \%$

West: Mountain Division $\quad 14.1 \%$

West: Pacific Division $\quad 20.9 \%$

Note: Percentages may not sum to exactly $100 \%$ due to rounding. All financial values are reported as mean values in 2009 dollars.

${ }^{\text {a }}$ Nine regions where clients reside:

Northeast: New England Division (CT, ME, MA, NH, RI, VT)

Northeast: Middle Atlantic Division (NY, NJ, PA)

South: South Atlantic Division (DE, DC, FL, GA, MD, NC, SC, VA, WV)

South: East South Central Division (AL, KY, MS, TN)

South: West South Central Division (AR, LA, OK, TX)

Midwest: East North Central Division (IL, IN, MI, OH, WI)

Midwest: West North Central Division (IA, KS, MN, MO, NE, ND, SD)

West: Mountain Division (AZ, CO, ID, MT, NV, UT, WY, NM)

West: Pacific Division (AK, CA, HI, OR, WA, GUAM) 
TABLE 2

Financial Profile of Online Bankruptcy Counseling Clients $(N=32,554)$

\author{
Mean Percentages
}

\title{
Reasons for financial problems
}

Unexpected expenses

$74.1 \%$

Loss of employment (unemployed, employer reduced hours, or spouse out of a job)

$52.1 \%$

Unnecessary spending

$49.8 \%$

Health problems / injury / illness

$36.4 \%$

Business loss / excessive business expenses $\quad 25.9 \%$

Divorce or separation

$21.8 \%$

Death of a spouse or other loved one

\section{Financial events in last 12 months}

$\begin{array}{ll}\text { Used one credit card to pay off another } & 47.8 \%\end{array}$

Delayed housing/auto payments to make credit card payments $\quad 36.8 \%$

Used a payday loan, rent-to-own, title loan, or other high interest rate loan $\quad 29.7 \%$

Had property repossessed or home foreclosed

Previous actions taken to deal with financial problems

Decreased expenses (budgeting, cutting back)

Borrowed money from family or friends

Renegotiated terms and conditions of existing loan(s)

$47.1 \%$

Increased income (worked more hours, took second job)

$38.7 \%$

Consolidated debts

$37.4 \%$

Cashed out or borrowed against retirement funds

$37.3 \%$

Refinanced home or applied for another loan

$31.1 \%$

Sold home, car, or other possessions

$28.2 \%$

Previously filed for bankruptcy

$27.1 \%$

Contacted a credit counseling service

Participated in a debt management plan (DMP)

Did not take any action / had no options

Willingness to do the following to improve financial situation

Reduce expenses (stop eating out, eliminate vacations)

$98.3 \%$

Increase income (get a second job, work more hours)

$78.5 \%$

Make lifestyle adjustments (downsize to a smaller home, move in with family/friends)

$60.4 \%$

Note: For these questions, clients were given several options and asked to check all that applied. For this reason, percentages sum to more than $100 \%$. 
TABLE 3

Changes in Financial Knowledge for Online Bankruptcy Counseling Clients $(N=32,554)$

\begin{tabular}{lccc}
\hline & & & Net \\
Knowledge Statement & $\begin{array}{c}\text { Correct } \\
\text { Pre-Counseling }\end{array}$ & $\begin{array}{c}\text { \% Correct } \\
\text { Post-Counseling }\end{array}$ & $\begin{array}{c}\text { Change } \\
\text { in Knowledge }\end{array}$ \\
\hline
\end{tabular}

1. Goals should only be made for long-term plans

$68.4 \%$

$76.8 \%$

$+8.4 \% * * *$ such as homeownership, college tuition, or retirement.

2. Fixed expenses are expenses that typically change

$74.5 \%$

$85.0 \%$

$+10.5 \% * * *$

from month to month such as food, clothing, and utilities.

3. You are considered solvent if your assets are greater than your liabilities.

$74.2 \%$

$85.3 \%$

$+11.1 \% * * *$

4. Gross income is defined as the income after taxes and

$81.6 \%$

$87.8 \%$

$+6.2 \% * * *$

other withholdings have been subtracted from net income.

5. A debt-to-income ratio of more than $20 \%$ may indicate that you have borrowed too much relative to your income.

$73.2 \%$

$92.9 \%$

$+19.7 \% * * *$

6. The cost of credit is determined by the interest rate,

$88.8 \%$

$92.7 \%$

$+3.9 \% * * *$

repay the loan.

7. Unsecured loans are loans that are tied to property or collateral.

$88.2 \%$

$90.6 \%$

$+2.4 \% * * *$

8. The best way to improve your credit score is to pay your bills on time and in full every month.

$86.4 \%$

$92.5 \%$

$+6.1 \% * * *$

9. Under the Fair Credit Reporting Act (FCRA), you are

$91.5 \%$

$94.3 \%$

$+2.7 \% * * *$ eligible to receive a free credit report once a year from each of the three credit reporting agencies.

10. All information, including a bankruptcy filing, must be removed from your credit report after 7 years.

${ }^{a}$ Net change in knowledge is defined as the difference between the pre- and post-test knowledge scores.

${ }^{\mathrm{b}}$ Average knowledge score $=($ Total correct/Number of knowledge statements $)$

$* \mathrm{p}<0.10 ; * * \mathrm{p}<0.05 ; * * * \mathrm{p}<0.01$ (The significance level, $p$, indicates whether differences in pre- and post-test values were statistically significant based on a two-tailed t-test.) 
TABLE 4

Changes in Financial Practices for Online Bankruptcy Counseling Clients $(N=32,554)$ How often are you currently doing (planning to do)
the following financial practices?

$\begin{array}{cc}\text { Mean } & \text { Mean } \\ \text { Behavior Score } & \text { Behavior Score } \\ \text { Pre-Counseling } & \text { Post-Counseling }\end{array}$

3.21

2.18

3.59

3.79

4.10

3.75

4.73

3.59

3.72

4.81

4.08

4.79

2.56

4.77

2.16

4.69

4.66

2.48

4.57

4.59

4.76

4.70

\section{4}

12. Checking your credit report and credit score.

39.18

56.35

Average Total Behavior Score ${ }^{\mathrm{c}}$

Note: Clients were asked to report how often they were currently doing (or planned to do) each financial practice. Responses were based on a 5-point Likert scale, ranging from $1=$ Never to 5=Always. To see which clients were more likely to have higher behavior scores, see Appendix A3 for regression analysis related to clients' financial practices.

${ }^{\text {a }}$ Clients were asked to report pre-counseling how often they were currently doing each financial practice. The mean behavior score pre-counseling reflects clients' responses on average to the 5-point Likert scale.

${ }^{\mathrm{b}}$ Following the counseling, clients were asked to report how often they planned to do each financial practice. The mean behavior score post-counseling again reflects clients' responses on average to the 5-point Likert scale.

${ }^{c}$ A client's total behavior score was calculated by summing all of the behavior scores for the 12 financial behaviors using the reported values based on the 5-point Likert scale. A client's total behavior score could range anywhere from 12 to 60, with higher scores reflecting more positive financial behaviors or more positive behavioral intentions. The average total behavior score is the total behavior score averaged over the entire sample of online counseling clients. 
TABLE 5

Perceived Educational Impact of the Online Bankruptcy Counseling Course (Post-Counseling, $N=32,554)$

As a result of the online counseling course.....

Did clients feel more knowledgeable about the bankruptcy process?

Yes

$98.0 \%$

No

$2.0 \%$

Did clients feel more knowledgeable about the options available to deal with their current financial problems?

Yes

$97.4 \%$

No

Did clients feel their overall ability to improve their financial behaviors changed?

Increased

$91.4 \%$

Decreased

$0.7 \%$

Stayed the same

$7.9 \%$

Overall, how helpful did clients find the online counseling course?

Very helpful

$44.3 \%$

Helpful

$43.8 \%$

Somewhat helpful

$11.3 \%$

Not helpful

$0.6 \%$

How likely were clients to recommend the online counseling course to others?

Very likely

$40.2 \%$

Likely

$41.7 \%$

Somewhat likely

$15.1 \%$

Not likely

$3.1 \%$

How likely were clients to seek credit counseling in the future if they had financial problems again?

Very likely

$43.7 \%$

Likely

$41.2 \%$

Somewhat likely

$12.3 \%$

Not likely

$2.9 \%$

Note: Percentages may not sum to $100 \%$ due to rounding. 
TABLE 6

OLS Regressions for Financial Knowledge and Behavior for Online Bankruptcy Counseling Clients $(N=32,554)$

\begin{tabular}{|c|c|c|}
\hline \multirow[b]{2}{*}{ Independent Variables } & $\begin{array}{l}\text { Post-Counseling } \\
\text { Knowledge Score }\end{array}$ & $\begin{array}{l}\text { Post-Counseling } \\
\text { Behavior Score } \\
\text { for Planned Behavior }\end{array}$ \\
\hline & Coeff SE & Coeff \\
\hline \multicolumn{3}{|l|}{ Prior Knowledge \& Behavior } \\
\hline Pre-counseling knowledge score & $0.6482(0.0080) * * *$ & -.---- $\quad(-.----)$ \\
\hline Pre-counseling behavior score & -.---- $\quad(-.----)$ & $0.1451(0.0048) * * *$ \\
\hline \multicolumn{3}{|l|}{ Age $(\%)$} \\
\hline Under 26 & $1.0736(0.4358) * *$ & $0.0255(0.1991)$ \\
\hline $26-35$ & $1.1437(0.2577) * * *$ & $0.1091(0.1115)$ \\
\hline $36-45$ & $0.3828(0.2386)$ & $0.1170(0.1022)$ \\
\hline $46-55$ & $0.3006(0.2440)$ & $0.1195(0.1050)$ \\
\hline \multicolumn{3}{|l|}{ Gender (\%) } \\
\hline Female & $-0.4868(0.1476) * * *$ & $0.5446(0.0668) * * *$ \\
\hline \multicolumn{3}{|l|}{ Marital Status (\%) } \\
\hline Married & $0.2905(0.2112)$ & $0.3075(0.0992) * * *$ \\
\hline Divorced/Separated & $0.5224(0.2294) * *$ & $0.1281(0.1067)$ \\
\hline Widowed & $1.0946(0.5405) * *$ & $0.1026(0.2426)$ \\
\hline \multicolumn{3}{|l|}{ Race/Ethnicity (\%) } \\
\hline African-American/Black & $-1.7463(0.2451) * * *$ & $-0.4719(0.1322) * * *$ \\
\hline Hispanic/Latino & $-3.7513(0.2826) * * *$ & $-0.4630(0.1209) * * *$ \\
\hline Asian/Pacific Islanders & $-1.6924(0.3674) * * *$ & $-1.7599(0.2008) * * *$ \\
\hline Other & $-0.8182(0.4081) * *$ & $-0.7756(0.1979) * * *$ \\
\hline \multicolumn{3}{|l|}{ Education Level (\%) } \\
\hline Less than high school & $-5.0276(0.4641) * * *$ & $-0.7756(0.1979) * * *$ \\
\hline High school (or GED) & $-1.5729(0.2025) * * *$ & $-0.8721(0.0888) * * *$ \\
\hline Some college & $-0.6073(0.1690) * * *$ & $-0.2166(0.0720) * * *$ \\
\hline \multicolumn{3}{|l|}{ Household Income (\%) } \\
\hline$\$ 20,001-\$ 40,000$ & $1.1610(0.2289) * * *$ & $0.4769(0.1092) * * *$ \\
\hline$\$ 40,001-\$ 60,000$ & $2.0351(0.2548) * * *$ & $0.9233(0.1193) * * *$ \\
\hline$\$ 60,001-\$ 80,000$ & $2.5755(0.2921) * * *$ & $1.1405(0.1344) * * *$ \\
\hline Over $\$ 80,000$ & $3.0437(0.3233) * * *$ & $1.3080(0.1475) * * *$ \\
\hline \multicolumn{3}{|l|}{ Homeownership (\%) } \\
\hline Homeowner & $0.5162(0.1663) * * *$ & $0.4494(0.0753) * * *$ \\
\hline \multicolumn{3}{|l|}{ Employment Status $(\%)$} \\
\hline Working full-time & $-0.0561(0.1995)$ & $-0.1006(0.0892)$ \\
\hline Working part-time & $-0.1060(0.2717)$ & $-0.0154(0.1178)$ \\
\hline \multicolumn{3}{|l|}{ Willingness to Make Change (\%) } \\
\hline Make lifestyle adjustments & $-0.0707(0.1555)$ & $0.5580(0.0703) * * *$ \\
\hline
\end{tabular}


TABLE 6 (continued)

OLS Regressions for Financial Knowledge and Behavior for Online Bankruptcy Counseling Clients $(N=32,554)$

\begin{tabular}{|c|c|c|}
\hline \multirow[b]{2}{*}{ Independent Variables } & $\begin{array}{l}\text { Post-Counseling } \\
\text { Knowledge Score }\end{array}$ & $\begin{array}{l}\text { Post-Counseling } \\
\text { Behavior Score } \\
\text { for Planned Behavior }\end{array}$ \\
\hline & Coeff SE & Coeff SE \\
\hline \multicolumn{3}{|l|}{ Reasons for Financial Problems (\%) } \\
\hline Health problems/injury/illness & $0.5525(0.1490) * * *$ & $0.1438(0.0668) * *$ \\
\hline Loss of employment & $0.5421(0.1540) * * *$ & $0.4065(0.0695) * * *$ \\
\hline Engaged in unnecessary spending & $0.7967(0.1458) * * *$ & $0.6881(0.0710) * * *$ \\
\hline \multicolumn{3}{|l|}{ Financial Events in Last 12 months (\%) } \\
\hline Used a payday/high interest loan & $-0.6816(0.1636) * * *$ & $0.1614(0.0753) * *$ \\
\hline $\begin{array}{l}\text { Delayed house/auto payments } \\
\text { to pay credit cards }\end{array}$ & $-0.5563(0.1516) * * *$ & $0.0948(0.0688)$ \\
\hline $\begin{array}{l}\text { Had property repossessed } \\
\text { or home foreclosed }\end{array}$ & $-0.1348(0.1694)$ & $-0.0896(0.0780)$ \\
\hline \multicolumn{3}{|l|}{ Repeat Bankruptcy Filer } \\
\hline Previously filed bankruptcy & $-0.0701(0.1664)$ & $-0.2131(0.0779) * * *$ \\
\hline \multicolumn{3}{|l|}{$\begin{array}{l}\text { Socioeconomic Controls } \\
\text { (Census county-level data) }\end{array}$} \\
\hline$\%$ urban population & $-1.1155(0.3964) * * *$ & $-0.0829(0.1693)$ \\
\hline$\%$ less than high school education & $-2.1139(1.9126)$ & $-1.3314(0.8604)$ \\
\hline ln (median house value) & $-0.6128(0.2795) * *$ & $-0.3539(0.1255) * * *$ \\
\hline Intercept & $43.6908(3.5862) * * *$ & $53.5446(1.5783) * * *$ \\
\hline Census Regions & YES & YES \\
\hline R-squared & 0.4578 & 0.0615 \\
\hline
\end{tabular}

Note: "Coeff" represents coefficients and "SE" represents standard errors. Robust standard errors are reported for each regression. Omitted categories include: over 55 years of age, male, single/never married, Caucasian/white, college or graduate degree, household income $\$ 20,000$ or less, and not currently working. Nine census regions were included in the estimation of the models but the results are not reported in the tables. These results are available upon request.

$* \mathrm{p}<0.10 ; * \mathrm{p}<0.05 ; * * * \mathrm{p}<0.01$ 